Article

\title{
The Combined Effect of Indoor Air Quality and Socioeconomic Factors on Health in Northeast China
}

\author{
Yu Chen and Bin Chen * \\ Laboratory of Building Environment and New Energy Resource, School of Civil Engineering, \\ Dalian University of Technology, Dalian 116024, China; yuchen2035@163.com \\ * Correspondence: chenbin@dlut.edu.cn
}

Received: 19 March 2020; Accepted: 15 April 2020; Published: 19 April 2020

\begin{abstract}
Research has increasingly demonstrated that complex relationships exist between residential indoor air quality, health and socioeconomic factors. However, few studies have provided a comprehensive understanding of these relationships. The purpose of this paper, therefore, was to use structural equation modeling to identify the combined effect of residential indoor air quality and socioeconomic factors on occupants' health, based on field measurement data in Northeast China. The results showed that socioeconomic status had a direct impact on the occupants' health with the path coefficient of 0.413 , whereas the effect from indoor air quality was 0.105 . Socioeconomic status posed the direct effect on indoor air quality with path coefficients of 0.381 . The weights of $\mathrm{PM}_{2.5}, \mathrm{CO}_{2}$, TVOC (Total Volatile Organic Compounds), and formaldehyde concentration to the indoor air quality were $0.813,0.385,0.218$, and 0.142 , respectively. Relative contributions of Income level, education level, and occupation prestige to socioeconomic status were $0.595,0.551$, and 0.508 , respectively. Relationships between indoor air quality, socioeconomic factors and health were further confirmed based on multiple group analysis. The study defines and quantifies complex relationships between residential indoor air quality, socioeconomic status and health, which will help improve knowledge of the impacts of the residential indoor environment on health.
\end{abstract}

Keywords: indoor air quality; socioeconomic factors; health; Northeast China; residential buildings

\section{Introduction}

China's rapid economic growth, urbanization, and industrialization over the past four decades has increased concern about air pollution. It was estimated that air pollution in China could lead to approximately 1.6 million deaths in 2015 [1], and cost 1.4 trillion dollar in 2010 [2]. Moreover, millions of Chinese people in modern society spend about $83.3 \%$ of their time indoors (such as residences, office buildings, schools, daycare centers and public spaces) [3]. Approximately $67 \%$ of the time spent indoors is spent in their residences [4], and the figure is even higher during the outbreak of novel coronavirus pneumonia epidemic currently. The indoor air quality in residential buildings has far-reaching implications for occupants' health and wellbeing.

Considerable scientific progress has been made in the understanding of health effects related to the indoor air quality over the past decades. These efforts tend to address indoor air pollution sources and exposures and associated health concerns, such as sulfur dioxide [5], nitrogen oxides [6], ozone [7], particulate matter [8], formaldehyde [9], radon [10], tobacco smoke [11], VOC [12], pesticides [13] and SVOC (Semi-Volatile Organic Compounds) [14]. More recently, research has increasingly shown the effect of socioeconomic factors (e.g., income, education, and job) on the relationship between indoor air quality and occupants' health. On the one hand, socioeconomic factors can influence indoor air pollution exposures directly. For example, low-income families were likely to live in dilapidated houses with deteriorating building structures and poor inferiors building materials, which led to high 
indoor air pollution levels [15]. Crowding was highly associated with low household economic status, which can increase high indoor air pollution level [16]. The education level may affect residential indoor air exposures, as it provided access to information on building maintenance, household hygiene, and the proper use of indoor consumer products [17]. On the other hand, socioeconomic factors, such as income, education, and occupation, have been recognized as the determinants of health [18]. For instance, a large body of research has suggested that people with higher education and income level tend to have better health [19]. One of the reasons was that these socioeconomic factors influenced the access to health care and nutrition [20].

Complex relationships exist between residential indoor air quality, health and socioeconomic factors. Few studies have identified the combined effects of residential indoor air quality and socioeconomic factors on occupants' health. There are multiple indoor air pollution exposures in the residential housing simultaneously, leading to multiple adverse health problems. Moreover, socioeconomic factors cannot be concretely defined like weight or length, because of involving several aspects, e.g., income, education, and job status. However, the standard regression-based models have limited ability to interpret the complexity. For example, Brown et al. applied multivariate regression to examine the associations between socioeconomic factors and indoor pollutant levels in French dwellings [17]. Rumchev et al. proposed a multivariable Poisson regression model to establish the relationship between socioeconomic status, indoor air pollution and respiratory symptoms in South India [21]. Schlink et al. developed a quantile regression model to analyze the link between education level of the occupants and indoor volatile organic compounds concentrations in Germany [22]. Byun et al. used the general linear model to identify the effects of socioeconomic factors on indoor $\mathrm{PM}_{10}$ concentrations in Korea [23]. Such models only allow expressing the relations between one dependent variable and multiple independent variables. Moreover, there are often the high correlations among socioeconomic or indoor air pollution indicators (i.e., multi-collinearity), resulting in models being incorrectly estimated. Structural equation modeling (SEM) is a powerful statistical method that can disentangle the complex network of relations between a set of variables. It identifies the relationships between multiple dependent variables and independent variables simultaneously, even in the face of multi-collinearity. SEM has been applied increasingly in the indoor environment quality (IEQ) research over the past decade. For instance, Loupa et al. used the SEM method for analyzing the association of IEQ and self-rated symptoms of employees in three Greek hospitals [24]. Tharim et al. identified the link between IEQ, occupants' satisfaction and productivity in GBI rated office Building based on PLS-SEM [25]. Kamaruzzaman et al. applied the SEM approach to determine which indoor environmental factor had the most significant impact on occupants' satisfaction [26]. Finell et al. explored whether indoor air problems observed in schools associated with students' perceptions of the teacher-student relationship and class spirit [27].

The purpose of this paper, therefore, is to identify the combined effects of indoor air quality and socioeconomic factors on health based on structural equation modeling, using the field measurement data in Northeast China. This study will promote a comprehensive understanding of the impact of indoor air pollution on health, which would provide benefits in controlling indoor air pollution.

\section{Materials and Methods}

\subsection{Data Source}

Field measurement was conducted in six major cities (Harbin, Changchun, Shenyang, Jinzhou, Anshan, and Qiqihar) of Northeast China. Northeast China, as China's traditional industrial base, has a total population of about 100 million people, and is mainly located in the severe cold climate region. The cities were chosen on the basis of population distribution. Figure 1 presents the population density of Northeast China in accordance with China's Sixth National Population Census in 2010 [28]. The population densities of Harbin, Changchun, Shenyang, Jinzhou, and Anshan are all higher than 300 people per square kilometer, and Qiqihar is slightly lower (200-300 people per square kilometer). 
A total of 81 residential buildings were selected by the method of random digit dialing. All residential indoor environment were continuously monitored from 20 November 2014 to 24 February 2015 during winter central heating which is supplied by the government.

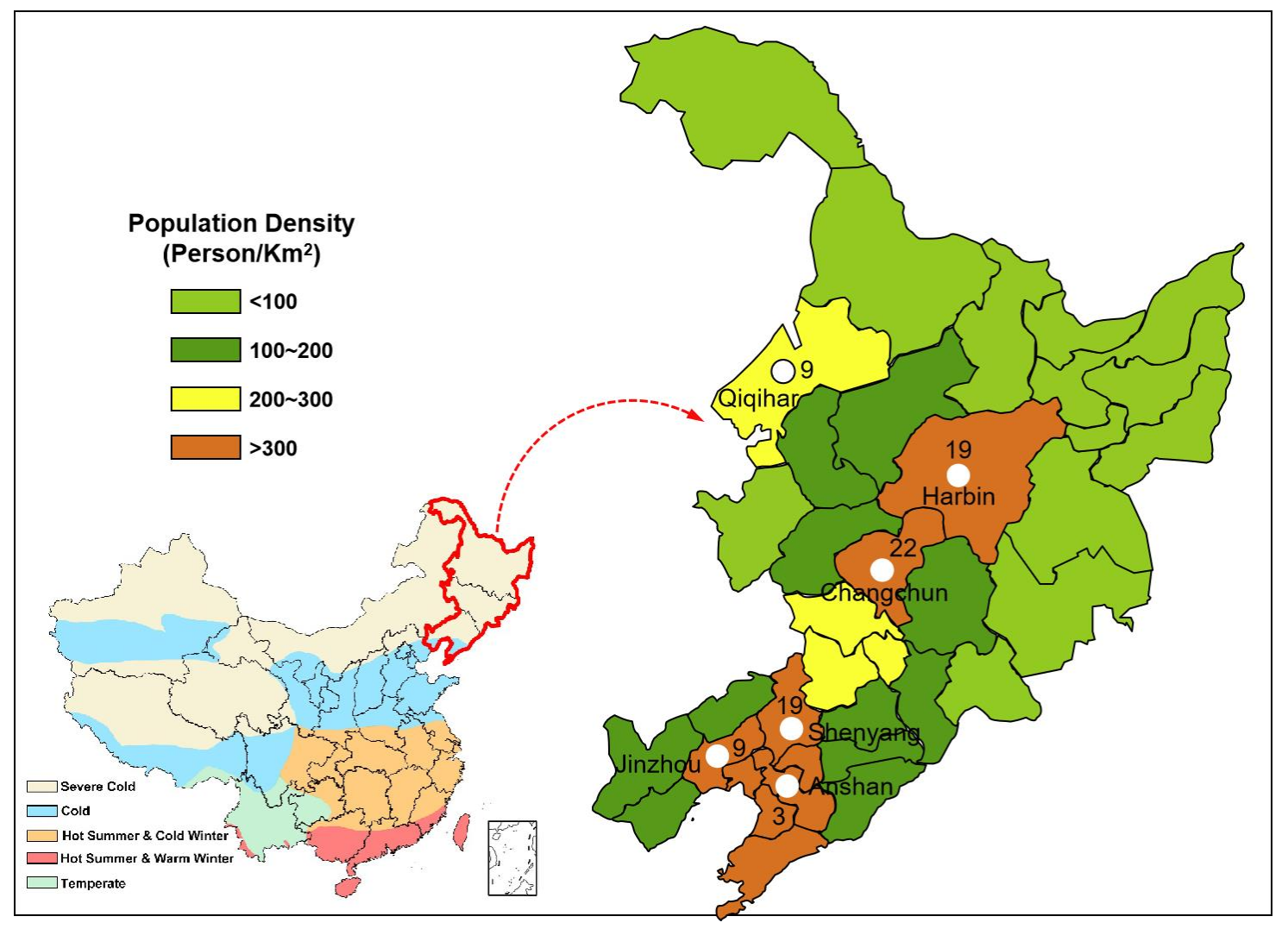

Figure 1. The population density of Northeast China and the number of investigated residential buildings.

The investigation of residential indoor environment consisted of two parts: Measurements of indoor air environment parameters and a self-administered questionnaire survey. $\mathrm{CO}_{2}, \mathrm{PM}_{2.5}$, TVOC, and formaldehyde concentration were selected as the criteria for indoor air quality. Because $\mathrm{CO}_{2}$ concentration is a good indicator of contamination caused by persons indoors, while TVOC, and formaldehyde $(\mathrm{HCHO})$ concentration are indicators for indoor air pollution by building materials and fittings [29]. $\mathrm{PM}_{2.5}$ concentration represents the source of indoor air contamination caused by particulate matter. Table 1 shows the characteristics of measuring instruments. Indoor air parameters were monitored at the breathing zone height, i.e., $1.1 \mathrm{~m}$ above the floor, as recommended by the National Indoor Air Quality Standard (GB/T 18883-2002) [30]. Moreover, indoor environmental parameters were measured simultaneously in the living room, bedroom, kitchen to represent the conditions of the indoor environment accurately. The measurement data were recorded every five or ten minutes.

Table 1. Characteristics of instruments for measuring the indoor environment parameters.

\begin{tabular}{cccc}
\hline Indicator & Instrument & Range & Accuracy \\
\hline $\mathrm{CO}_{2}$ & MCH-383SD & $0 \sim 4000 \mathrm{ppm}$ & $\pm 5 \%$ \\
$\mathrm{PM}_{2.5}$ & SHINYEI PM SENSOR & $1 \sim 1000 \mu \mathrm{g} / \mathrm{m}^{3}$ & $\pm 1 \%$ \\
$\mathrm{HCHO}$ & SHINYEI IAQ SENSING & $0 \sim 5 \mathrm{mg} / \mathrm{m}^{3}$ & $\pm 2 \%$ \\
TVOC & GC112A & $0 \sim 1000 \mathrm{ppm}$ & $\pm 2 \%$ \\
\hline
\end{tabular}


The self-administered questionnaire included health variables, socioeconomic status, lifestyle and personal characteristics:

- $\quad$ Health variables: Health was measured by the widely used tool—the Short Form 8 Health Survey (SF-8) (as shown in Table S1). The reliability and validity of the Chinese version of the SF-8 Health Survey were confirmed [31]. The SF-8 Health Survey includes physical and mental components, and each component covers four sub-scales, the physical health: Physical functioning (PF), role physical (RP), bodily pain (BP) and general health (GH); the mental health: Vitality (VT), social functioning (SF), role emotional (RE) and mental health (MH). For example, role emotional refers to 'have you had problems with your work or other regular daily activities (such as walking or climbing stairs) as a result of any emotional problems?' Bodily pain indicates 'how much bodily pain have you had?' Each sub-scale was scored on a scale of 1 to 4 (1 represents the worst and 4 the best health status).

- Socioeconomic status: Socioeconomic factors are typically determined by the level of education, income, and occupation prestige [32]. This survey used the combinations of education level $(1=$ 'primary school', $2=$ 'middle school', $3=$ 'professional', $4=$ 'university', $5=$ 'master, $\mathrm{PhD}$, or specialization'), income level ( $1=$ 'low': $<5000$ yuan/month, $2=$ 'middle':5000 10,000 yuan/month, 3 = 'high': $>10,000$ yuan/month), and occupation prestige ( $1=$ 'low', 2 = 'middle', $3={ }^{\prime}$ high') as the measurement.

- $\quad$ Lifestyle: smoking status and alcohol consumption ('Frequently' $=0$, 'Sometimes' $=1$, 'Rarely' $=$ 2, and 'Not at all' = 3);

- Personal characteristics: Gender, age, and length of residence

\subsection{Structure Equation Modeling}

Structural equation modeling was used to define and quantify complex relations between the residential indoor air quality, socioeconomic status and health, as shown in Figure 2. It consists of two main components: (1) The measurement model showing the relations between latent variables (indoor air quality, socioeconomic status, and health as shown in the ellipses) and their measurement indicators (as shown in the rectangles); (2) the structural model, which imputes relations between the latent variables (indoor air quality, socioeconomic status, and health).

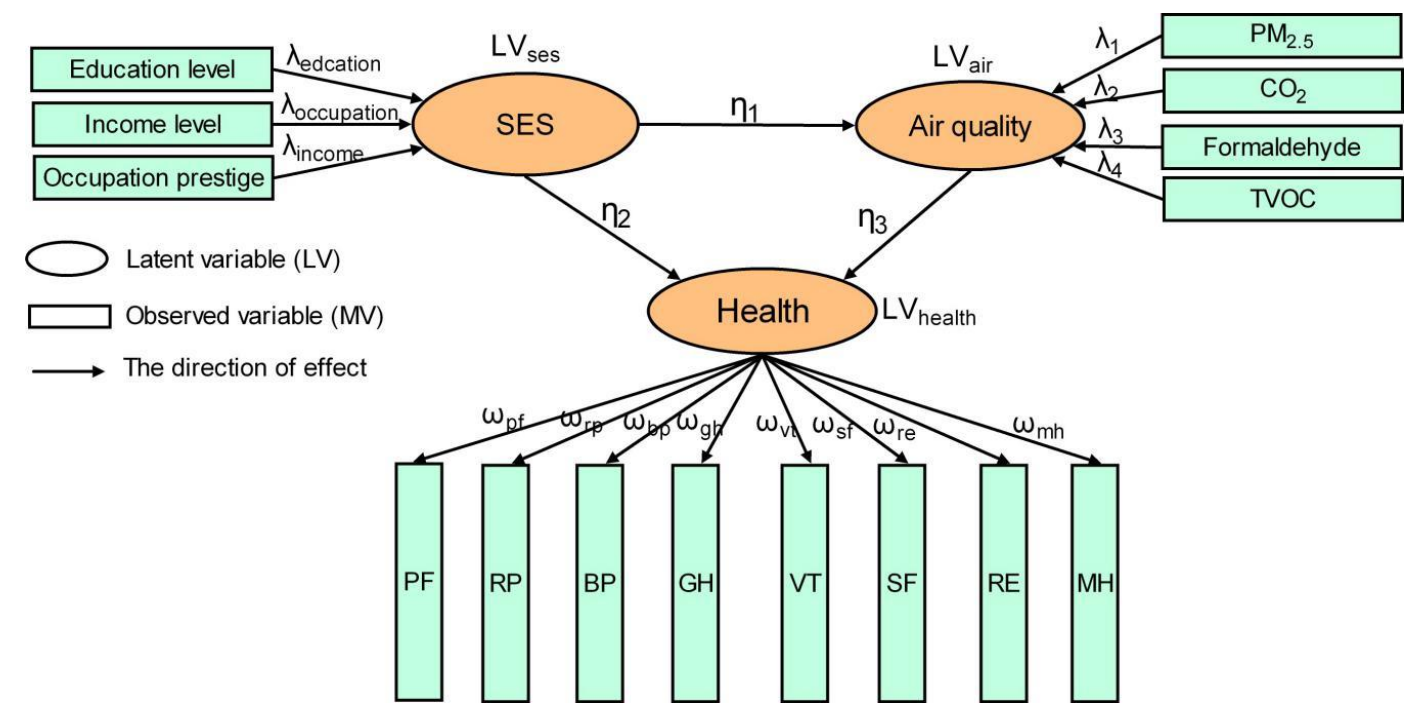

Figure 2. The theoretical model used for characterizing relations between indoor air quality, socioeconomic status and health. SES-socioeconomic status; Air quality-indoor air quality; PF-physical functioning; RP-role physical; BP-bodily pain; GH—general health; VT_vitality; $\mathrm{SF}$-social functioning; RE—-role emotional; $\mathrm{MH}$-mental health. 


\subsubsection{The Measurement Model}

There are two types of measurement models in Figure 2: the reflective model (the direction of the arrow: Latent variables $\rightarrow$ observed variables) and the formative model (the direction of the arrow: observed variables latent variables). This depends on the appropriate relationship is between latent variables and their indicators [33]. For example, the indoor air environment includes $\mathrm{CO}_{2}$, $\mathrm{PM}_{2.5}$, TVOC, and formaldehyde concentration. It is difficult to use a single index that quantifies an individual's response to all these factors [34]. Hence, the indoor air quality was measured by combining these factors to form an index in the formative model. While the measurement indicators of health, such as physical functioning (PF), role physical (RP), and bodily pain (BP), were manifestations of health in the reflective model. The details are shown as follows.

In formative models, the latent variable (LV) is defined by the corresponding observable variables (MVs) in full [35]. The LV is a liner function of MVs,

$$
\mathrm{LV}=\sum \lambda \mathrm{MV}
$$

where $\lambda$ determines the relative contribution of an observable variable to the corresponding latent variable, and is called the outer weight. The range of $\lambda$ is $[-1,1]$. Conversely, the MV is associated with the corresponding LV by a liner regression in the reflective model.

$$
\mathrm{MV}=\omega \mathrm{LV}+\delta
$$

where $\omega$ shows the absolute contribution of an observable variable to the corresponding latent variable, and is called the outer loading. The range of $\omega$ is also $[-1,1]$. The $\delta$ represents the measurement error.

\subsubsection{The Structural Model}

The relationships between latent variables including indoor air quality $\left(L V_{\text {air }}\right)$, socioeconomic status $\left(L V_{\text {ses }}\right)$ and health $\left(L V_{\text {health }}\right)$, were described by the structure model (Figure 2$)$. The details are showed as follows,

$$
\begin{gathered}
L_{\text {health }}=\eta_{3} L V_{\text {air }}+\eta_{2} L V_{\text {ses }}+\sigma_{\text {health }} \\
L_{\text {air }}=\eta_{1} L V_{\text {ses }}+\sigma_{\text {air }}
\end{gathered}
$$

where $\eta$ is equivalent to standardized betas in a linear regression model, and is called the path coefficient. The $\sigma$ represents the measurement error.

The model was estimated based on the partial least squares SEM (PLS-SEM) algorithm using the software SmartPLS 3.0 [36]. The PLS-SEM algorithm is generally superior to others when formatively measured latent variables are part of the structural models and the sample size is small [37]. According to the PLS-SEM algorithm, the measurement models and the structural model were combined. The algorithm maximized the explained variance of the dependent latent variables to estimate the model parameters. Henseler et al. provided a detailed description of the algorithm [38]. The average values of indoor air environmental parameters during the measuring period were imported into the model, as well as the corresponding questionnaire data (health variables and socioeconomic status). It should be noted that the average values of indoor environmental parameters cannot be imported into the model directly. This is because the dimensions of indoor air environment parameters are not uniform. To overcome this problem, we classified the indoor environment into four categories according to the EN 15,251 Standard [39]. Categories I to III indicate the high level, normal level, and acceptable level of expectation, respectively. Category IV represents values outside the criteria for the above categories. Categories I to IV are scored on a scale of 4 to 1 , whereby 1 represents the lowest and 4 the highest performance. Table 2 shows the parameter limit values for the indoor air quality categories. The categories of $\mathrm{CO}_{2}$ were defined on the basis of the EN 15,251 Standard. The chosen concentrations of $\mathrm{PM}_{2.5}$ were derived from US EPA (Environmental Protection Agency) [40]. 
The categories of parameter limit values for formaldehyde and TVOC were defined by the Classification of Indoor Climate 2000: Target Values, Design Guidance and Product Requirements [41]. Finally, the mean values of indoor air environment parameters were scored from 1 to 4 on the basis of Table 2 .

Table 2. Parameter limit values for the indoor environmental quality categories.

\begin{tabular}{ccccc}
\hline \multirow{2}{*}{ Indicator } & \multicolumn{4}{c}{ Category } \\
\cline { 2 - 5 } & I & II & III & IV \\
\hline $\mathrm{CO}_{2}(\mathrm{ppm})$ & 700 & $700-850$ & $850-1150$ & $>1150$ \\
$\mathrm{PM}_{2.5}\left(\mu \mathrm{g} / \mathrm{m}^{3}\right)$ & 15 & $15-40$ & $40-65$ & $>65$ \\
$\mathrm{HCHO}\left(\mu \mathrm{g} / \mathrm{m}^{3}\right)$ & $<30$ & $30-65$ & $65-100$ & $>100$ \\
$\mathrm{TVOC}\left(\mu \mathrm{g} / \mathrm{m}^{3}\right)$ & $<200$ & $200-400$ & $400-600$ & $>600$ \\
\hline
\end{tabular}

\subsubsection{Model Evaluation}

On the basis of the results of the computation, the model should be evaluated. Hair et al. provided a detailed description of how to assess PLS-SEM results of reflective measurement models, formative measurement models, and the structural model [37]. The formative measurement models are assessed on their significance and relevance $(p$ value $<0.05)$, and the presence of collinearity among indicators (variance inflation factor, VIF $<5$ ). Reflective measurement models are evaluated by the composite reliability (as a mean to evaluate the internal consistency reliability, $>0.7$ ), convergent validity (average variance extracted, AVE $>0.5$ ), and discriminant validity (Fornell-Larcker criterion, average variance extracted should exceed the squared correlation with any other latent variables). The evaluation of the structural model results involved collinearity issues (variance inflation factor, VIF $<5$ ), significance and relevance of the structural model relationships ( $p$ value $<0.05$ ), predictive accuracy (coefficients of determination, $>0.2$ ), and predictive relevance (Stone-Geisser's $Q^{2}$ value, $>0$ ).

\section{Results}

\subsection{The Houses Measured and Respondents}

Table 3 illustrates the information on the houses measured and respondents' characteristics. About $69.2 \%$ of residential buildings were completed in 2000 or after. The percent of number of people per floor area above 0.02 in the investigated buildings was $81.5 \%$. A total of 151 respondents participated in the survey. Approximately $52.4 \%$ of the respondents were women. The age of most of the subjects $(66.9 \%)$ ranged from 30 to 50 years. A total of $33.8 \%$ of respondents had a middle school education or less. Most respondents (74.8\%) resided in the surveyed buildings for more than five years. With regard to their lifestyle, $70.8 \%$ of the subjects reported no smoking and $36.2 \%$ no drinking.

\subsection{Description of the Indoor Air Pollution Level}

Figure 3 depicts the distribution of average values of each indoor air environment parameter during the measuring period for all the investigated houses. The median $\mathrm{CO}_{2}$ level was $901.1 \mathrm{ppm}$ (25th percentile: $677.4 \mathrm{ppm}$; 75th percentile: $1263.2 \mathrm{ppm}$ ). The lowest level was $309.61 \mathrm{ppm}$, and the highest level was $3239.31 \mathrm{ppm}$. The median concentration of TVOC was $0.28 \mathrm{mg} / \mathrm{m}^{3}$ (25th percentile: $0.14 \mathrm{mg} / \mathrm{m}^{3}$; 75th percentile: $0.29 \mathrm{mg} / \mathrm{m}^{3}$ ). The highest and lowest values were $0.04 \mathrm{mg} / \mathrm{m}^{3}$ and $1.3 \mathrm{mg} / \mathrm{m}^{3}$, respectively. Formaldehyde levels ranged from $3.1 \mu \mathrm{g} / \mathrm{m}^{3}$ and $81.4 \mu \mathrm{g} / \mathrm{m}^{3}$ (25th percentile: $13.9 \mu \mathrm{g} / \mathrm{m}^{3}$; 50th percentile: $21.0 \mu \mathrm{g} / \mathrm{m}^{3}$; 75th percentile: $30.5 \mu \mathrm{g} / \mathrm{m}^{3}$ ). The median $\mathrm{PM}_{2.5}$ concentration was $42.0 \mu \mathrm{g} / \mathrm{m}^{3}$ (25th percentile: $30.0 \mu \mathrm{g} / \mathrm{m}^{3}$; 75th percentile: $55.6 \mu \mathrm{g} / \mathrm{m}^{3}$ ) and ranged from $11.0 \mu \mathrm{g} / \mathrm{m}^{3}$ to $132.6 \mu \mathrm{g} / \mathrm{m}^{3}$. 
Table 3. The information on the houses measured and respondents.

\begin{tabular}{cccc}
\hline Information & $\mathbf{N}(\mathbf{\%})$ & Information & $\mathbf{N ~ ( \% )}$ \\
\hline Houses & & Education level & \\
Construction date & Master, PhD, or specialization & $26(17.2 \%)$ \\
Before 1990 & $9(11.1 \%)$ & University or Professional & $74(49.0 \%)$ \\
$1990-2000$ & $16(19.8 \%)$ & Middle school or less & $51(33.8 \%)$ \\
$2000-2010$ & $42(51.9 \%)$ & Length of residence & \\
After 2010 & $14(17.3 \%)$ & $\leq 5$ years & $38(25.2 \%)$ \\
Number of people per floor area (person $\left./ \mathrm{m}^{2}\right)$ & & $5 \sim 10$ years & $55(36.4 \%)$ \\
$\leq 0.02$ & $15(18.5 \%)$ & $\geq 10$ years & $58(38.4 \%)$ \\
$0.02-0.03$ & $22(27.2 \%)$ & Lifestyle & \\
$0.03-0.04$ & $21(25.9 \%)$ & Smoking status & $44(29.2 \%)$ \\
$\geq 0.04$ & $23(28.4 \%)$ & Yes & $107(70.8 \%)$ \\
Respondents & & No & $96(63.8 \%)$ \\
Sex & & Alcohol consumption & $55(36.2 \%)$ \\
Men & $72(47.7 \%)$ & No & \\
Women & $79(52.3 \%)$ & & \\
Age & & & \\
$\leq 30$ & $22(14.6 \%)$ & & \\
$30-50$ & $101(66.9 \%)$ & & \\
$\geq 50$ & $28(18.5 \%)$ & & \\
\hline
\end{tabular}

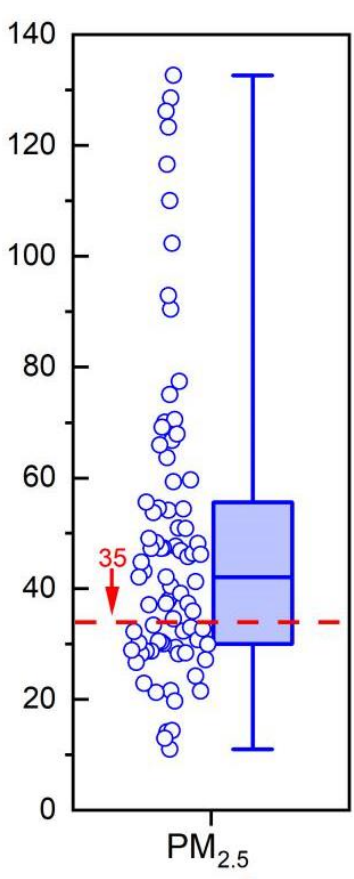

$\left(\mu \mathrm{g} / \mathrm{m}^{3}\right)$

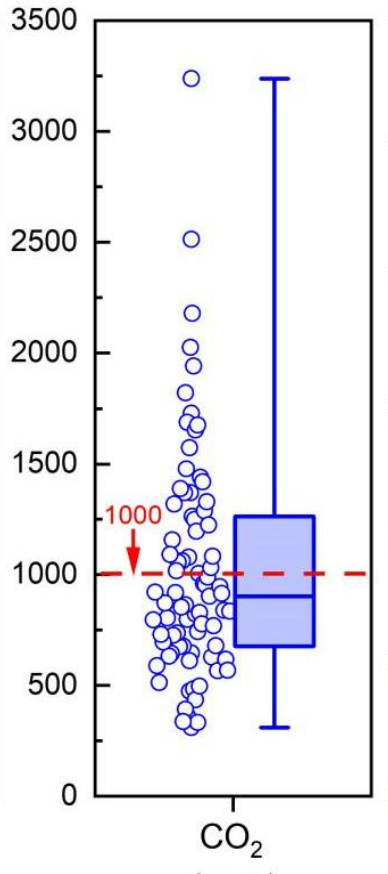

(ppm)
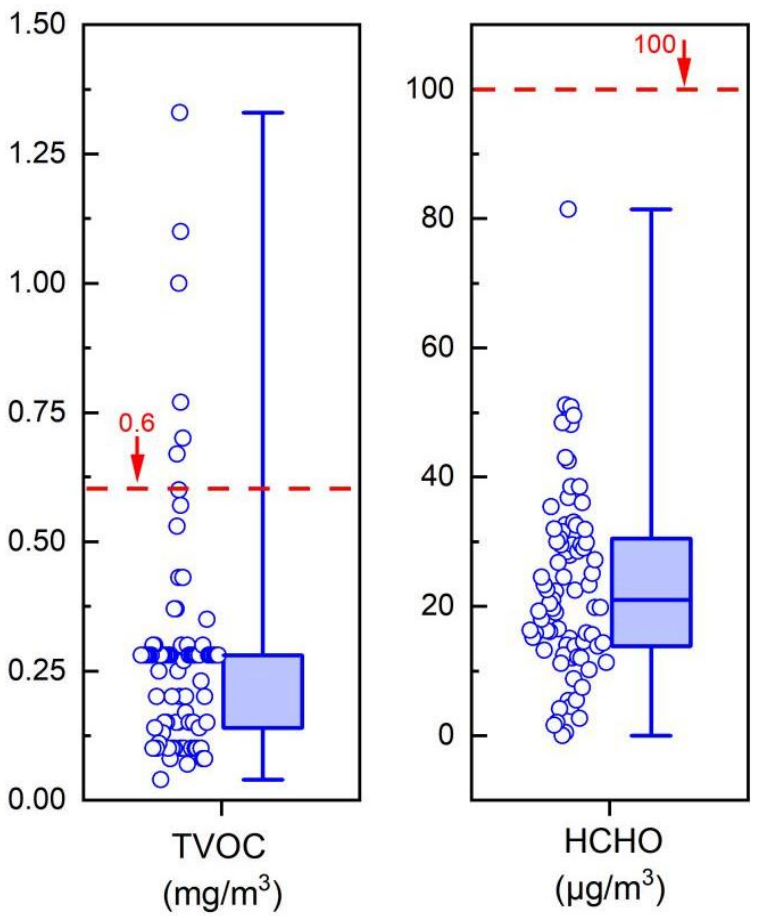

Figure 3. Distribution of the average values of indoor environmental parameters. Boxplots show medians, $25 \sim 75$ percentiles (box) and min-max (whiskers). The red dash lines indicate the standard value recommended by the National Indoor Air Quality Standard [30].

According to Figure 3, there were high levels of average $\mathrm{CO}_{2}$ and $\mathrm{PM}_{2.5}$ concentration for the investigated houses. As can be seen from Figures $\mathrm{S} 1$ and $\mathrm{S} 2, \mathrm{CO}_{2}$ concentration remained high, especially at night. There were $\mathrm{CO}_{2}$ and $\mathrm{PM}_{2.5}$ peak exposures during the period of time, such as cooking time. This was due to the fact that there was insufficient ventilation for most investigated houses. It was estimated that a large majority of residents opened windows for less than 10 min per day to avoid heat loss [42], and approximately $71 \%$ of homes had an air change rate lower than $0.5 \mathrm{~h}^{-1}$ in winter [43]. Moreover, there were a lack of mechanical ventilation systems in most residential 
buildings of Northeast China. Furthermore, burning coal was still the main source of central heating, leading to indoor and outdoor environmental pollution [44].

\subsection{Model Result and Evaluation}

Figure 4 shows the structural equation modeling results inferred from field measurement data. The results indicate that the indoor air quality posed a direct impact on the occupants' health with the path coefficient of 0.105 , whereas the effects from socioeconomic status were 0.413 . The effect of socioeconomic status on indoor air quality was 0.381 . As for the measurement model of the indoor air quality, the greatest weight came from $\mathrm{PM}_{2.5}(0.813)$, followed by $\mathrm{CO}_{2}(0.385)$, TVOC (0.218), and formaldehyde (0.142). Income level (0.595) was the major indicator contributing to socioeconomic status, followed by education level (0.551) and occupation prestige (0.508). With respect to the measurement model of health status, physical functioning $(0.849)$ had the greatest absolute contribution, followed by role emotional $(0.773)$, vitality $(0.736)$, role physical $(0.677)$, mental health $(0.565)$, general health (0.564), bodily pain (0.545), and social functioning (0.491).

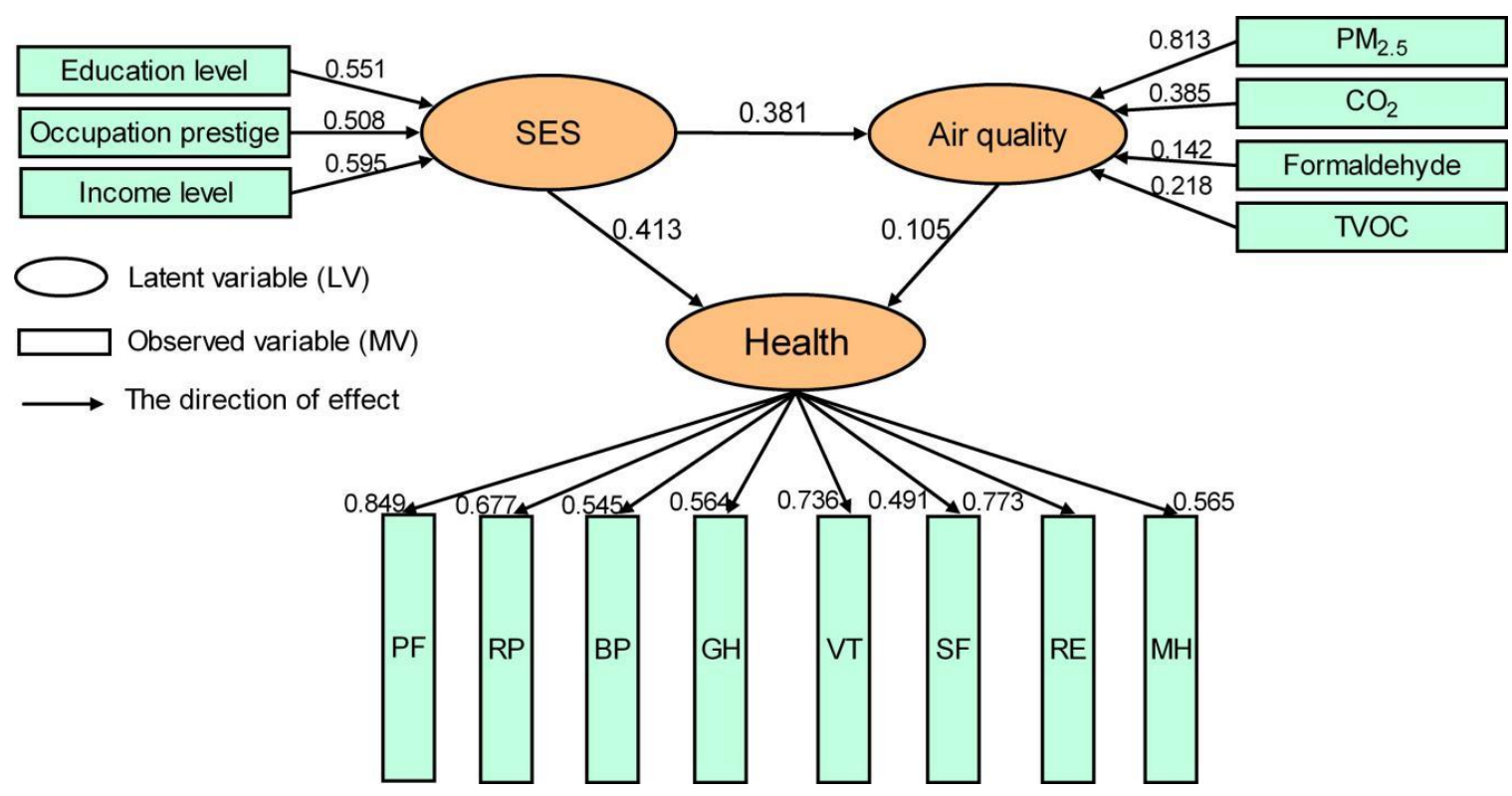

Figure 4. The model results inferred from the field measurement data (compared with Figure 3). SES- socioeconomic status; PF-physical functioning; RP-role physical; BP-bodily pain; GH-general health; VT-vitality; SF-social functioning; RE-role emotional; MH-mental health.

Table 4 summarizes the results of the model evaluation. In the formative measurement models, the indicators' variance inflation factor (VIF) were uniformly below the threshold value of 5 . Hence, the level of collinearity was very low. Moreover, all indicators in the formative models were significant $(p<0.01)$. In the reflective models, the values of composite reliability for health $(0.853)$ were larger than the threshold value of 0.7. The average variance extracted (AVE) were greater than the threshold value of 0.5 for health (0.637), confirming the convergent validity. The square roots of AVE, for health (0.798) were larger than its correlations with other variables, indicating a well-established discriminant validity. Finally, all VIF values were lower than the threshold value of 5, suggesting that the collinearity was also not an issue in the structure model. All relationships were significant in the structural model. The coefficients of determination for health $(0.305)$ and indoor air quality $(0.220)$ were above the threshold value of 0.2 . The predictive relevance values for the indoor air quality $(0.110)$ and health (0.283) were greater than the threshold value of 0 , proving the predictive relevance for the model. In summary, the model has met all requirements, thus proving that it was reliable and valid. 
Table 4. The model evaluation results (see Figure 4).

\begin{tabular}{|c|c|c|c|c|c|c|c|}
\hline \multicolumn{8}{|c|}{ Formative Measurement Model } \\
\hline $\begin{array}{c}\text { Latent } \\
\text { Variables }\end{array}$ & Indicators & $\begin{array}{c}\text { Outer } \\
\text { Weight }\end{array}$ & VIF & $\begin{array}{c}\text { Latent } \\
\text { Variables }\end{array}$ & Indicators & $\begin{array}{c}\text { Outer } \\
\text { Weight }\end{array}$ & VIF \\
\hline \multirow{4}{*}{ SES } & education level & $0.551 *$ & 1.011 & \multirow{4}{*}{ Air quality } & $\mathrm{PM}_{2.5}$ & $0.813 *$ & 1.039 \\
\hline & occupation prestige & $0.508 *$ & 1.005 & & $\mathrm{CO}_{2}$ & $0.385^{*}$ & 1.055 \\
\hline & income level & $0.595 *$ & 1.009 & & $\mathrm{HCHO}$ & $0.142 *$ & 1.050 \\
\hline & & & & & TVOC & $0.218 *$ & 1.072 \\
\hline \multicolumn{8}{|c|}{ Reflective Measurement Model } \\
\hline $\begin{array}{c}\text { Latent } \\
\text { Variables }\end{array}$ & Indicators & $\begin{array}{c}\text { Outer } \\
\text { Loading }\end{array}$ & \multicolumn{2}{|c|}{$\begin{array}{l}\text { Composite } \\
\text { Reliability }\end{array}$} & \multicolumn{2}{|c|}{$\begin{array}{l}\text { Discriminant } \\
\text { Validity }\end{array}$} & AVE \\
\hline \multirow{8}{*}{ Health } & physical functioning & 0.849 & \multirow{8}{*}{\multicolumn{2}{|c|}{0.853}} & \multirow{8}{*}{\multicolumn{2}{|c|}{ YES }} & \multirow{8}{*}{0.637} \\
\hline & role physical & 0.677 & & & & & \\
\hline & bodily pain & 0.545 & & & & & \\
\hline & general health & 0.564 & & & & & \\
\hline & vitality & 0.736 & & & & & \\
\hline & social functioning & 0.491 & & & & & \\
\hline & role emotional & 0.773 & & & & & \\
\hline & mental health & 0.565 & & & & & \\
\hline \multicolumn{8}{|c|}{ Structural Model } \\
\hline Relation & Path Coefficient & VIF & $\begin{array}{l}\text { Co } \\
\text { Det }\end{array}$ & $\begin{array}{l}\text { ficient of } \\
\text { mination }\end{array}$ & \multicolumn{3}{|c|}{ Predictive Relevance } \\
\hline IAQ $\rightarrow$ Health & $0.105 *$ & 1.136 & & .305 & \multicolumn{3}{|c|}{0.283} \\
\hline SES $\rightarrow$ Health & $0.413 *$ & 1.216 & & .305 & \multicolumn{3}{|c|}{0.283} \\
\hline $\mathrm{SES} \rightarrow \mathrm{IAQ}$ & $0.381 *$ & 1.272 & & .220 & \multicolumn{3}{|c|}{0.110} \\
\hline
\end{tabular}

\section{Discussion}

\subsection{Link Between Socioeconomic Factors, Indoor Air Quality, and Health}

This paper confirmed the complex relationship between socioeconomic factors, indoor air quality and occupants' health (Figure 4). Socioeconomic factors (0.413) had a stronger direct impact on health than indoor air quality (0.105). Although, there is no literature that specifically indicates the relative weight of socioeconomic factors or indoor air quality to health, research has increasingly pointed out that the contribution of socioeconomic factors (e.g., education, income, and work conditions) was beyond physical environment (e.g., air quality and drinking water). For example, America's Health Rankings estimated that the weight of socioeconomic factors $(0.27)$ to health was three times as great for physical environment (0.09) [45]. County Health Rankings established the relative contribution of socioeconomic factors (0.4) and physical environment (0.1) on health [46]. The University of Wisconsin Population Health Institute assigned weights to health as follows: Socioeconomic factors, 0.4; physical environment, 0.05 [47]. Unfortunately, there is no consensus on the relative contribution of socioeconomic factors or physical environment on health. But the weight of physical environment is rather weaker than socioeconomic factors.

Income level $(0.595 \times 0.413=0.246)$, education level $(0.551 \times 0.413=0.228)$, and occupation prestige $(0.508 \times 0.413=0.209)$ delivered the similar weight to health. This may be due to the interplay among the three factors. More education level is usually connected to higher income level and better employment options [48]. It is estimated that each additional year of schooling can increase approximately $11 \%$ more income every year [49]. Higher income jobs usually provide not only a safe work environment, but also health insurance and paid sick leave [50]. As for indoor air quality, $\mathrm{PM}_{2.5}$ concentration $(0.813 \times 0.105=0.085)$ was the major indicator contributing to health, followed by $\mathrm{CO}_{2}(0.385 \times 0.105=0.04)$, TVOC $(0.218 \times 0.105=0.02)$ and formaldehyde $(0.142 \times 0.105=0.01)$. The weighting distributions can be explained as follows. Approximately $61.7 \%$ of the average $\mathrm{PM}_{2.5}$ concentration exceeded $35 \mu \mathrm{g} / \mathrm{m}^{3}$ specified by WHO air quality guidelines [51], as shown in Figure 3 . The average $\mathrm{CO}_{2}$ level were above 1000 ppm (National Indoor Air Quality Standard GB18883-2002 [30]) 
in nearly $40.7 \%$ of the investigated houses. Only $7.4 \%$ of homes failed to reach TVOC concentration standard $\left(0.6 \mathrm{mg} / \mathrm{m}^{3}\right.$, National Indoor Air Quality GB18883-2002). Furthermore, the formaldehyde in all the houses were below $100 \mu \mathrm{g} / \mathrm{m}^{3}$ (National Indoor Air Quality GB18883-2002). As can be seen, TVOC and formaldehyde, as the indicators for indoor air pollution by building materials and fittings [29], are not major indoor air pollutants in the investigated houses. The primary reason is that about $82.8 \%$ of residential buildings were completed in 2010 or before (Table 3). Indoor air pollution from $\mathrm{PM}_{2.5}$ and $\mathrm{CO}_{2}$ (the indicator of contamination caused by persons) has presented a noteworthy challenge. Moreover, $\mathrm{CO}_{2}$ concentration was related to the density of people indoors (as shown in Figure S3). About $42 \%$ of the variance in the indoor $\mathrm{CO}_{2}$ concentration can be explained by the number of persons per floor area.

Socioeconomic factors, including income level $(0.595 \times 0.381=0.227)$, education $(0.551 \times 0.381=0.209)$, and occupation prestige $(0.508 \times 0.381=0.194)$, shared the similar contribution to indoor air quality. According to Table 5, $\mathrm{PM}_{2.5}$ and $\mathrm{CO}_{2}$ concentration both decreased steadily, with the growth of education level. For example, $\mathrm{PM}_{2.5}$ and $\mathrm{CO}_{2}$ concentration dropped by $8.4 \%$ and $10.4 \%$, respectively, from middle school less to university or professional subgroup. Despite some minor fluctuations, TVOC and $\mathrm{HCHO}$ concentration showed the downward trend. For income level and occupantion group, $\mathrm{PM}_{2.5}$ and $\mathrm{CO}_{2}$ concentration both followed a similar decline pattern. TVOC concentration generally still maintained the decrease. $\mathrm{HCHO}$ concentration fluctuated slightly. Furthermore, it can be found that there were significant differences for smoking status among the education level subgroups. A total of $45.0 \%$ of respondents reported smoking in the middle school or less subgroup, but the proportion dropped sharply to just $15.3 \%$ for the master, $\mathrm{PhD}$, or specialization group. A large body of research has demonstrated that smoking has the great influence on pollutants indoors [52]. It was estimated that increases of $\mathrm{PM}_{2.5}$ concentration in homes with smokers ranged from 25 to $45 \mu \mathrm{g} / \mathrm{m}^{3}$ [53]. Smoking also strongly influenced the indoor concentration of VOC $(p<0.05)$ [54]. Moreover, smoking was known to have significant effects on health, such as carcinogenic, reproductive, and/or acute or chronic respiratory effects. For example, Canadian Tobacco, Alcohol and Drugs Survey revealed that around $52.5 \%$ of current smokers reported 'excellent' or 'very good' health, compared to $58 \%$ of former smokers, and significantly lower than $69 \%$ of never smokers [55]. Arday et al. estimated the effect of cigarette smoking on health among 26,504 American high school seniors, and found that respondents who were regular smokers were significantly more likely to report shortness of breath, coughing spells, productive cough, and wheezing or gasping [56]. There were no significant differences for household size among the income level subgroups, i.e., high income level (2.21), middle income level (2.12), and low income level (2.21). However, the average floor area in the high level income subgroup was $144.9 \mathrm{~m}^{2}$, which was much higher than low level income subgroup $\left(68.7 \mathrm{~m}^{2}\right)$. Hence, crowding may be common in the low level subgroup, leading to high indoor air pollutant level.

Table 5. The $\mathrm{PM}_{2.5}, \mathrm{CO}_{2}$, TVOC, and $\mathrm{HCHO}$ concentration in the different education, income and occupation level.

\begin{tabular}{|c|c|c|c|c|c|}
\hline \multirow[b]{2}{*}{ Item } & \multirow[b]{2}{*}{ Content } & \multicolumn{4}{|c|}{ Mean \pm SD } \\
\hline & & $\begin{array}{c}\mathrm{PM}_{2.5} \\
\left(\mu \mathrm{g} / \mathrm{m}^{3}\right)\end{array}$ & $\begin{array}{c}\mathrm{CO}_{2} \\
(\mathrm{ppm})\end{array}$ & $\begin{array}{c}\text { TVOC } \\
\left(\mathrm{mg} / \mathrm{m}^{3}\right)\end{array}$ & $\begin{array}{l}\mathrm{HCHO} \\
\left(\mathrm{ug} / \mathrm{m}^{3}\right)\end{array}$ \\
\hline \multirow{3}{*}{ Education } & Master, $\mathrm{PhD}$, or specialization (26) & $42.67 \pm 20.16$ & $954.19 \pm 398.83$ & $0.23 \pm 0.13$ & $21.57 \pm 13.35$ \\
\hline & University or Professional (74) & $47.04 \pm 28.57$ & $986.47 \pm 464.41$ & $0.23 \pm 0.10$ & $21.44 \pm 11.20$ \\
\hline & Middle school or less (51) & $51.35 \pm 29.83$ & $1100.48 \pm 581.42$ & $0.33 \pm 0.26$ & $23.10 \pm 15.34$ \\
\hline \multirow{3}{*}{ Income } & High (47) & $38.19 \pm 25.32$ & $897.54 \pm 369.73$ & $0.23 \pm 0.12$ & $19.49 \pm 13.24$ \\
\hline & Middle (56) & $42.98 \pm 18.80$ & $982.74 \pm 402.66$ & $0.21 \pm 0.12$ & $25.56 \pm 15.43$ \\
\hline & Low (48) & $62.71 \pm 32.51$ & $1180.05 \pm 669.20$ & $0.35 \pm 0.25$ & $21.35 \pm 10.99$ \\
\hline \multirow{3}{*}{ Occupantion } & High (52) & $43.35 \pm 22.08$ & $928.67 \pm 414.64$ & $0.23 \pm 0.11$ & $23.31 \pm 14.87$ \\
\hline & Middle (50) & $49.81 \pm 30.19$ & $1051.38 \pm 475.13$ & $0.24 \pm 0,10$ & $22.42 \pm 13.92$ \\
\hline & Low (49) & $49.88 \pm 30.08$ & $1083.10 \pm 588.81$ & $0.32 \pm 0.27$ & $21.04 \pm 12.20$ \\
\hline
\end{tabular}




\subsection{Multiple Group Analysis}

The initial model (Figure 4) was tested to determine variances in the model relationships by the multi-group analysis based on gender, age, and length of residence. Table 6 shows the distributions of path coefficients for these subgroups. The mean path coefficients (standard deviation) for the effects of socioeconomic status and indoor air quality on health were $0.373 \pm 0.055$, and $0.166 \pm 0.052$, for gender, respectively; $0.404 \pm 0.023$ and $0.156 \pm 0.040$, for age, respectively; $0.408 \pm 0.062$ and $0.138 \pm 0.029$, respectively, for length of residence. The impacts of socioeconomic status on indoor air quality were $0.321 \pm 0.017,0.359 \pm 0.060$, and $0.347 \pm 0.029$, respectively, for gender, age, and length of residence. There were not a great deal of difference between above results and the initial model (Figure 4), i.e., $0.413,0.105$, and 0.381 , correspondingly. Additionally, it can be found that there was stronger relationship between indoor air quality and health for shorter length of residence. Perhaps this was due to the fact that $\mathrm{CO}_{2}, \mathrm{VOC}$ and formaldehyde concentration all decreased steadily with the growth of the length of residence. For example, VOC and formaldehyde concentration dropped by $36 \%$ and $4.1 \%$, respectively, from ' $<5$ years' to ' $5-10$ years' subgroup.

Despite the fluctuation of path coefficients for the gender, age, and length of residence subgroup, the complex interactions among indoor air quality, health, and socioeconomic status were verified.

Table 6. The distributions of path coefficients for gender, age, and length of residence.

\begin{tabular}{ccccc}
\hline Item & Content & SES $\rightarrow$ Health & IAQ $\rightarrow$ Health & SES $\rightarrow$ IAQ \\
\hline \multirow{4}{*}{ Gender } & Men & 0.427 & 0.217 & 0.337 \\
& Women & 0.318 & 0.114 & 0.304 \\
& Average & 0.373 & 0.166 & 0.321 \\
& SD & 0.055 & 0.052 & 0.017 \\
\hline \multirow{4}{*}{ Age } & $\leq 30$ years & 0.427 & 0.141 & 0.440 \\
& 30 50 years & 0.381 & 0.116 & 0.343 \\
& $\geq 50$ years & 0.405 & 0.210 & 0.295 \\
& Average & 0.404 & 0.156 & 0.359 \\
SD & 0.023 & 0.040 & 0.060 \\
\hline \multirow{4}{*}{ Length of residence } & SD years & 0.467 & 0.173 & 0.333 \\
& 5-10 years & 0.454 & 0.136 & 0.374 \\
& A years & 0.354 & 0.107 & 0.336 \\
& Average & 0.408 & 0.138 & 0.347 \\
The initial model & 0.062 & 0.029 & 0.029 \\
\hline
\end{tabular}

Note: SES—socioeconomic status; IAQ—indoor air quality; SD—standard deviation " $\rightarrow$ "—direction of the effect.

\subsection{Strengths and Limitations}

This study was successful in its approach, resulting in an association model between the residential indoor air quality, socioeconomic factors, and health based on the 'real-world' data (field measurement data). The model reflected the combined effect of residential indoor air quality and socioeconomic factors on health. Moreover, indoor air quality and socioeconomic factors were measured by the combination of multiple factors.

However, some limitations in this study should be noted. First, the model results may not reflect all residential indoor environment conditions in Northeast China because of the sampling error. In fact, it is difficult to carry out the large-scale measurement of residential indoor environment because of the privacy and funding. Considering the lifestyle of residents and climate in Northeast China was partly similar, this study selected 81 residences in six densely populated cities. Second, the measurement of occupants' health status was only performed by self-reporting. There are differences between respondents' self-reported health and their actual health status. But self-reported health is a widely used measure to predict health outcomes [57]. It has been consistently shown to predict morbidity and mortality, even after accounting for objective health status, behavioral risk 
factors, and sociodemographic characteristics [58], and mortality is considered as the most objective measurement of the general health of an individual [59]. Moreover, self-rated health has been found to be a reliable measurement of general health, since respondents rated the same general health assessment within a period where their health was unlikely to change [60]. However, it should be noted that health effects are seldom momentaneous. Most effects do not appear at the first exposure and do not disappear immediately after the exposure stops. The same was true for the 'health effects' measured in this study. Hence, there may be a risk that this study overestimated factors which would not change in a short time (such as socioeconomic factors) compared with those which would change over time (such as indoor air pollution factors). This problem will be considered in future studies. In addition, it is necessary to emphasize that this study identified the association model between residential indoor air quality, socioeconomic factors and self-reported health using the SEM method. But the association is not synonymous with causality. The causality of identified relations should also be confirmed in future research.

\section{Conclusions}

This study reports the combined effect of residential indoor air quality and socioeconomic factors on health, using structural equation modeling, on the basis of field measurements in Northeast China. The following conclusions were derived:

(1) The indoor air quality and socioeconomic status had the direct effect on the occupants' health with path coefficients of 0.105 , and 0.413 , respectively. Socioeconomic status posed the direct effect on indoor air quality with path coefficients of 0.381 .

(2) Income level, education level, and occupation prestige shared the similar weight to socioeconomic status, i.e., $0.595,0.551$, and 0.508 , respectively. Relative contributions of $\mathrm{PM}_{2.5}$, $\mathrm{CO}_{2}$, TVOC, and formaldehyde concentration to indoor air quality were $0.813,0.385,0.218$, and 0.142 , respectively.

(3) Relationships between indoor air quality, socioeconomic factors and health were further confirmed for selected data groups (gender, age, and length of residence) using multiple group analysis.

Supplementary Materials: The following are available online at http://www.mdpi.com/2076-3417/10/8/2827/s1, Figure S1: $\mathrm{CO}_{2}$ concentration in the selected residential buildings, Figure S2: $\mathrm{PM}_{2.5}$ concentration in the selected residential buildings, Figure S3: The relation between the number of persons per floor area and average $\mathrm{CO}_{2}$ concentration for all the investigated houses, Table S1: The Short Form 8 Health Survey.

Author Contributions: Conceptualization, B.C. and Y.C.; methodology, B.C. and Y.C.; software, Y.C.; validation, Y.C.; formal analysis, B.C. and Y.C.; investigation, B.C. and Y.C.; resources, B.C.; data curation, B.C. and Y.C.; writing - original draft preparation, Y.C.; writing-review and editing, B.C. and Y.C.; supervision, B.C.; project administration, B.C.; funding acquisition, B.C. All authors have read and agreed to the published version of the manuscript.

Funding: This work was supported by the National Natural Science Foundation of China (No.51578103 and No. 51978121); the Key Projects in the National 'Twelfth Five-Year' Science and Technology Support Program of China (No.2012BAJ02B05); and the '13th Five-Year' National Science Technology Major Project of China (No.2018YFD1100701).

Acknowledgments: The authors wish to thank for Xueyan Zhang, Xiang Li, Xinying Fan, Xiumei Li, Min Zhou, Yuhang Shu, Yuanbin Zhu assistance with the field measurement.

Conflicts of Interest: The authors declare no conflict of interest.

\section{References}

1. Forouzanfar, M.H.; Afshin, A.; Alexander, L.T.; Anderson, H.R.; Bhutta, Z.A. Global, regional, and national comparative risk assessment of 79 behavioral, environmental and occupational, and metabolic risks or clusters of risks, 1990-2015: A systematic analysis for the Global Burden of Disease Study 2015. Lancet 2016, 388, 1659-1724. [CrossRef]

2. Organization for Economic Co-operation and Development. The Cost of Air Pollution: Health Impacts of Road Transport; OECD Publishing: Paris, France, 2014; pp. 1-8. 
3. Duan, X.L.; Zhao, X.G.; Wang, B.B. Highlights of the Chinese Exposure Factors Handbook (Adults); Science Press: Beijing, China, 2015; pp. 89-90.

4. Brasche, S.; Bischof, W. Daily time spent indoors in German homes-Baseline data for the assessment of indoor exposure of German occupants. Int. J. Hyg. Environ. Health 2005, 208, 247-253. [CrossRef]

5. Liu, Y.L.; Luo, K.L.; Li, L.; Shahid, M.Z. Fluoride and sulfur dioxide indoor pollution situation and control in coal-burning endemic area in Zhaotong, Yunnan, China. Atmos. Environ. 2013, 77, 725-737. [CrossRef]

6. Kornartit, C.; Sokhi, R.S.; Burton, M.A.; Ravindra, K. Activity pattern and personal exposure to nitrogen dioxide in indoor and outdoor microenvironments. Environ. Int. 2010, 36, 36-45. [CrossRef]

7. Mitchell, C.S.; Zhang, J.F.; Sigsgaard, T.; Jantunen, M.; Lioy, P.J.; Samson, R.; Karol, M.H. Current State of the Science: Health Effects and Indoor Environmental Quality. Environ. Health Perspect. 2007, 115, 958-964. [CrossRef]

8. Morawska, L.; Afshari, A.; Bae, G.N.; Buonanno, G.; Chao, C.Y.H.; Hanninen, O.; Hofmann, W.; Isaxon, C.; Jayaratne, E.R.; Pasanen, P.; et al. Indoor aerosols: From personal exposure to risk assessment. Indoor Air 2013, 23, 462-487. [CrossRef] [PubMed]

9. Huang, S.D.; Wei, W.J.; Weschler, L.B.; Salthammer, T.; Kan, H.D.; Bu, Z.M.; Zhang, Y.P. Indoor formaldehyde concentrations in urban China: Preliminary study of some important influencing factors. Sci. Total Environ. 2017, 590, 394-405. [CrossRef] [PubMed]

10. Chen, D.Y.; You, X.B.; Hu, R.Y. Indoor radon survey in indoor environments in Zhuhai city, China. Radiat. Meas. 2005, 39, 205-207.

11. Weschler, C.J. Changes in indoor pollutants since the 1950s. Atmos. Environ. 2009, 43, 153-169. [CrossRef]

12. Weschler, C.J. Chemistry in indoor environments: 20 years of research. Indoor Air 2011, 21, 205-218. [CrossRef]

13. Lewis, R.G. Pesticides. In Indoor Air Quality Handbook; Spengler, J.D., Samet, J.M., Eds.; McGraw-Hill: New York, NY, USA, 2001; Volume 1, pp. 1-21.

14. Wang, L.X.; Zhao, B.; Liu, C.; Lin, H.; Yang, X.; Zhang, Y.P. Indoor SVOC pollution in China: A review. Chin. Sci. Bull. 2010, 55, 1469-1478. [CrossRef]

15. Arcus-Arth, A.; Broadwin, R.; Lam, R. Impact of Socioeconomic Factors on Residential Indoor Air Quality and Human Health. In Environmental Toxicology and Human Health; Tetsuo, S., Ed.; Encyclopedia of Life Support Systems: Oxford, UK, 2009; Volume 2, pp. 126-154.

16. Gordon, S.B.; Bruce, N.G.; Grigg, J.; Hibberd, P.L.; Kurmi, O.P.; Lam, K.B. Respiratory risks from household air pollution in low and middle income countries. Lancet Respir. Med. 2014, 2, 823-860. [CrossRef]

17. Brown, T.; Dassonville, C.; Derbez, M.; Ramalho, O.; Kirchner, S.; Crump, D.; Mandin, C. Relationships between socioeconomic and lifestyle factors and indoor air quality in French dwellings. Environ. Res. 2015, 140, 85-396. [CrossRef] [PubMed]

18. Institute of Medicine. The Future of the Public's Health in the 21st Century; National Academies Press: Washington, DC, USA, 2002; pp. 26-28.

19. Friel, S.; Marmot, M.G. Action on the Social Determinants of Health and Health Inequities Goes Global. Annu Rev. Public Health 2011, 32, 225-236. [CrossRef]

20. Braveman, P.A.; Cubbin, C.; Egerter, S.; Williams, D.R.; Pamuk, E. Socioeconomic disparities in health in the United States: What the patterns tell us. Am. J. Public Health 2010, 14, 20-35. [CrossRef]

21. Rumchev, K.; Zhao, Y.; Spickett, J. Health Risk Assessment of Indoor Air Quality, Socioeconomic and House Characteristics on Respiratory Health among Women and Children of Tirupur, South India. Int. J. Environ. Res. Pub. He 2017, 14, 429. [CrossRef]

22. Schlink, U.; Thiem, A.; Kohajda, T.; Richter, M.; Strebel, K. Quantile regression of indoor air concentrations of volatile organic compounds (VOC). Sci. Toral Environ. 2010, 408, 3840-3851. [CrossRef]

23. Byun, H.; Bae, H.; Kim, D.; Shin, H.; Yoon, C. Effects of socioeconomic factors and human activities on children's PM10 exposure in inner-city households in Korea. Int. Arch. Occup. Environ. Health 2010, 83, 867-878. [CrossRef]

24. Loupa, G.; Fotopoulou, S.; Tsagarakis, K.P. A tool for analysing the interdependence of indoor environmental quality and reported symptoms of the hospitals' personnel. J. Risk Res. 2017, 20, 678-691. [CrossRef]

25. Tharim, A.H.A.; Samad, M.H.A.; Ismail, M. Relationship between Indoor Environmental Quality (IEQ), Occupant's Satisfaction and Productivity in GBI Rated Office Building using SEM-PLS. Pertanika J. Soc. Sci. Hum. 2017, 25, 319-329. 
26. Kamaruzzaman, S.N.; Egbu, C.O.; Zawawi, E.M.A.; Karim, S.B.A.; Woon, C.J. Occupants' satisfaction toward building environmental quality: Structural equation modeling approach. Environ. Monit. Assess. 2015, 187, 242. [CrossRef] [PubMed]

27. Finell, E.; Tolvanen, A.; Haverinen-Shaughnessy, U.; Laaksonen, S.; Karvonen, S.; Sund, R.; Luopa, P.; Pekkanen, J.; Stahl, T. Indoor air problems and the perceived social climate in schools: A multilevel structural equation analysis. Sci. Total Environ. 2018, 624, 1504-1512. [CrossRef] [PubMed]

28. National Bureau of Statistics. Available online: http://www.stats.gov.cn/tjsj/pcsj/rkpc/6rp/indexch.htm (accessed on 3 February 2020).

29. Jokl, M.V. Indoor Air Quality Assessment Based on human Physiology-Part 3. Applications. Acta Polytech. 2003, 43, 38-46.

30. Inspection and Quarantine of the People's Republic of China; National health commission of the People's Republic of China. Indoor Air Quality Standard (GB/T 18883-2002); China Architecture \& Building Press: Beijing, China, 2002; pp. 1-12.

31. Lang, L.H.; Zhang, L.C.; Zhang, P.; Li, Q.; Jiang, B.; Guo, Y. Evaluating the reliability and validity of SF-8 with a large representative sample of urban Chinese. Health Qual. Life Outcome 2018, 16, 55-63. [CrossRef]

32. Ensminger, M.; Fotherill, K. A decade of measuring SES: What it tells us and where to go from here. In Socioeconomic Status, Parenting, and Child. Development; Bornstein, M., Bradley, R., Eds.; Lawrence Erlbaum: Mahwah, NJ, USA, 2003; pp. 25-36.

33. Jarvis, C.B.; MacKenzie, S.B.; Podsakoff, P.M. A critical review of construct indicators and measurement model misspecification in marketing and consumer research. J. Consum. Res. 2003, 30, 199-218. [CrossRef]

34. Humphreys, M.A. Quantifying occupant comfort: Are combined indices of the indoor environment practicable? Build. Res. Inf. 2005, 33, 317-325. [CrossRef]

35. Sarstedt, M.; Hair, J.F.; Ringle, C.M.; Thiele, K.O.; Gudergan, S.P. Estimation issues with PLS and CBSEM: Where the bias lies! J. Bus. Res. 2016, 69, 3998-4010. [CrossRef]

36. SmartPLS. Available online: https://www.smartpls.com/ (accessed on 18 January 2020).

37. Hair, J.F.; Hult, G.M.; Ringle, C.M.; Sarstedt, M. A Primer on Partial Least Squares Structural Equation Modeling (PLS-SEM); Sage: Los Angeles, LA, USA, 2014; pp. 95-205.

38. Henseler, J.; Chin, W.W. A comparison of approaches for the analysis of interaction effects between latent variables using partial least squares path modeling. Struct. Equ. Modeling 2010, 17, 82-109. [CrossRef]

39. European Committee for Standardization. Indoor Environmental Input Parameters for Design and Assessment of Energy Performance of Buildings Addressing Indoor Air Quality, Thermal Environment, Lighting and Acoustics (BS EN15251); European Committee for Standardization: Brussels, Belgium, 2007; pp. 11-51.

40. U.S. Environmental Protection Agency. Available online: http://www.epa.Gov/air/criteria.html (accessed on 5 February 2020).

41. Finish Society of Indoor Air Quality and Climate, Building Information Foundation RTS, Finnish Association of Architects, Finnish Association of Building Owners and Construction Clients, Finnish Association of Consulting Firms. Classification of Indoor Environment 2008: Target Values, Design Guidance and Product Requirements; Painotalo Trinket Oy: Helsinki, Finland, 2010.

42. Huang, K.L.; Feng, G.H.; Li, H.X.; Yu, S. Opening window issue of residential buildings in winter in north China: A case study in Shenyang. Energ. Build. 2014, 84, 567-574. [CrossRef]

43. Hou, J.; Zhang, Y.F.; Sun, Y.X.; Wang, P.; Zhang, Q.N.; Kong, X.R.; Sundell, J. Air change rates at night in northeast Chinese homes. Build. Environ. 2018, 132, 273-281. [CrossRef]

44. Huang, K.L.; Song, J.S.; Feng, G.H.; Chang, Q.P.; Jiang, B.; Wang, J.; Sun, W.; Li, H.X.; Wang, J.M.; Fang, X.S. Indoor air quality analysis of residential buildings in northeast China based on field measurements and long time monitoring. Build. Environ. 2018, 144, 171-183. [CrossRef]

45. America's Health Rankings. Available online: https://www.americashealthrankings.org/ (accessed on 7 February 2020).

46. Booske, B.C.; Athens, J.K.; Kindig, D.A.; Park, H.; Remington, P.L. Different perspectives for assigning weights to determinants of health. Univ. Wis. Popul. Health Inst. 2010, 1, 1-20.

47. Athens, J.K. Assessing the validity of health determinants in the Wisconsin County Health Rankings. Master's Thesis, University of Wisconsin: Madison, WI, USA, 2008.

48. Braveman, P.; Egerter, S.; Williams, D.R. The Social Determinants of Health: Coming of Age. Annu. Rev. Public Health 2011, 32, 381-398. [CrossRef] [PubMed] 
49. County Health Ranking \& Roadmaps. Available online: https://www.countyhealthrankings.org (accessed on 15 February 2020).

50. Gabel, J.; Levitt, L.; Holve, E.; Pickreign, J.; Whitemore, H. Job-based health benefifits in 2002: Some important trends. Health Aff. 2002, 21, 143-151. [CrossRef]

51. World Health Organization. Air Quality Guidelines for Particulate Matter, Ozone, Nitrogen, Dioxide and Sulfur Dioxide-Global Update 2005; World Health Organization Press: Geneva, Switzerland, 2005; pp. 10-12.

52. Ni, Y.M.; Shi, G.C.; Qu, J.M. Indoor $\mathrm{PM}_{2.5}$, tobacco smoking and chronic lung diseases: A narrative review. Environ. Res. 2020, 181, 1-10. [CrossRef]

53. Lance, W. Indoor Particles: A Review. J. Air Waste Manage. 1996, 46, 98-126.

54. Guo, H.; Lee, S.C.; Li, W.M.; Cao, J.J. Source characterization of BTEX in indoor micro environments in Hong Kong. Atmos. Environ. 2003, 37, 73-82. [CrossRef]

55. Tobacco Use in Canada. Available online: https://uwaterloo.ca/tobacco-use-canada/adult-tobacco-use (accessed on 16 February 2020).

56. Arday, D.R.; Giovino, G.A.; Schulman, J.; Nelson, D.E.; Mowery, P.; Samet, J.M. Cigarette smoking and self-reported health problems among U.S. high school seniors, 1982-1989. Am. J. Health Promot. 1995, 10, 111-117. [CrossRef]

57. Salomon, J.A.; Nordhagen, S.; Oza, S.; Murray, C.J. Are Americans feeling less healthy? The puzzle of trends in self-rated health. Am. J. Epidemiol. 2009, 170, 343-351. [CrossRef]

58. Lyyra, T.M.; Heikkinen, E.; Lyyra, A.L. Self-rated health and mortality: Could clinical and performance-based measures of health and functioning explain the association? Arch. Gerontol. Geriat. 2006, 42, 277-288. [CrossRef]

59. Amélie, Q.V. Self-rated health: Caught in the crossfire of the quest for 'true' health? Int. J. Epidemiol. 2007, 36, 1161-1164.

60. Qi, Y.Q. Reliability and Validity of Self-Rated General Health. Chn. J. Soc. 2004, 6, 196-215 (Chinese version).

(C) 2020 by the authors. Licensee MDPI, Basel, Switzerland. This article is an open access article distributed under the terms and conditions of the Creative Commons Attribution (CC BY) license (http://creativecommons.org/licenses/by/4.0/). 